\title{
Double hitch stitch is a novel technique for fixation of tracheal stent in a case of tracheoesophageal fistula: a case report
}

\author{
Sameer A. Arbat ${ }^{*}$ (D, Parimal S. Deshpande and Sweta R. Chourasia
}

\begin{abstract}
Background: Caudal tracheal stent migration can be potentially life threatening by causing distal luminal obstruction. We present a rare double hitch stitch procedure (for prevention of migration of tracheal stent), which is an external fixation technique in a case of tracheoesophageal fistula with tracheal and esophageal self-expandable metallic stent (SEMS).
\end{abstract}

Case presentation: A 50-year-old male patient who presented with cough and dyspnea was a known case of carcinoma of the esophagus with esophageal stent in situ. Computed tomography (CT) scan showed tracheoesophageal fistula with esophageal stent (esophageal SEMS) migrating into the trachea. Tracheal stenting was done with SEMS. Patient was followed up after 1 month with recurrent complaints of cough on deglutition. On follow-up bronchoscopy, migration of stent was observed. A rare procedure of double hitch stitch was performed with fixation of the tracheal stent (tracheal SEMS) using a percutaneous anchoring stitch, embedded in the subcutaneous tissue. Follow-up bronchoscopy after 1 month of the procedure showed no migration of stent.

Conclusion: For the treatment of large tracheoesophageal fistula, stenting of both the trachea and the esophagus along with the double hitch stitch proved to be lifesaving. Stent migration prevention using "double hitch-stitch" is simple, safe, and successful, without any complications.

Keywords: Double hitch stitch, Stent migration, Tracheoesophageal fistula, Case report

\section{Background}

Large airway obstruction due to malignant disease can be relieved with the use of silicone or metal stents [1]. Metal stents are more adherent to the tracheal wall than silicone stents [2] but still stent migration [3] is the major trouble in the case of tracheobronchial prostheses especially when it is placed in high or mid trachea without any proximal support. Stent migration could lead to obstruction of airway and in some cases can be fatal. Procedure of stent fixation becomes necessary. There are several types of stent fixators designed to avoid stent

\footnotetext{
* Correspondence: dr.sameerarbat@gmail.com

Department of Pulmonology, Ketki Research Institute of Medical Sciences, 275, Central Bazar Road, Ramdaspeth, Nagpur, Maharashtra State 440010, India
}

migration with different success rate, availability, cost or ease of the procedure, and cosmetic outcome [4-6]. The presence of an external scar can have variable acceptcently, there has been a report on "hitch stitch" method of stent migration prevention for the management of high tracheal stenosis [7].

\section{Case presentation}

A 50-year-old male Indian farmer, diagnosed with canwith complaints of recurrent lung infections. vegetarian, living an active life, ex-smoker, and extobacco chewer. He had a history of dysphagia for 5 months. His upper gastrointestinal endoscopy (UGIE) 
was done with sign of proliferative friable growth in the upper esophagus at $20 \mathrm{~cm}$ with complete luminal obstruction with no fistula. Computed tomography (CT) scan showed circumferential esophageal thickening involving upper half of the esophagus. However, mucosal biopsy result was non-specific. Endoscopic ultrasound (EUS) was done, which showed the sign of circumferential hypoechogenic growth in the esophagus involving all 3 layers. Fine needle aspiration cytology (FNAC) was diagnostic of squamous cell carcinoma. The patient underwent fully covered self-expandable metallic stent (SEMS) placement and subsequently received 6 cycles of chemotherapy. The patient was then referred to our center because of recurrent cough with mucoidal expectoration and pain in the throat region. On physical examination, patient was conscious, oriented, cooperative, and afebrile; heart rate was $92 \mathrm{bpm}$, blood pressure $100 / 60 \mathrm{mmHg}$, and $\mathrm{SpO}_{2} 98 \%$ on room air. Crackles were heard over the base of the right lung. Laboratory findings showed blood glucose level $117 \mathrm{mg} / \mathrm{dl}$. We started broad spectrum antibiotic therapy (piperacillintazobactam and clindamycin). Chest CT scan was done which showed a fistula between the esophagus and trachea at the proximal end of esophageal SEMS (Fig. 1). The first bronchoscopy (local anesthesia with lignocaine $4 \%$, via nasal route) showed two fistulous openings: one $3 \mathrm{~cm}$ below vocal cords on posterior wall of trachea and another one $1 \mathrm{~cm}$ above carina on the right tracheal wall. Thick secretions (mucoid in nature) were also observed in both the right and left bronchial tree; hence, bilateral bronchial washing was performed and sent to bacteriology. Tracheal stenting was suggested. Patient consent was taken, and after 2 days, second bronchoscopy with fluoroscopy was done by sedating the patient with midazolam, fentanyl, and propofol. There were thick secretions in bilateral bronchial tree. With the help of fluoroscopy, it was confirmed that the opening $1 \mathrm{~cm}$ above carina on the right tracheal wall was not a fistula but an anomalous opening to the right upper lobe in the trachea. Tracheoesophageal fistula (TOF) was seen $3 \mathrm{~cm}$ distal to the vocal cords. Hence, diagnosis of TOF was confirmed (Fig. 2).

We opted for tracheal fully covered self-expanding metallic stent (SEMS) $6 \mathrm{~cm}$ in size. Metallic stent was placed covering the fistula at proximal trachea $(2 \mathrm{~cm}$ distal to vocal cords), and the patient was discharged. After 20 days, patient returned complaining of cough on deglutition and with signs of lower respiratory tract infection. The follow-up bronchoscopy showed distal migration of tracheal SEMS exposing the fistulous opening. Repositioning of stent and its fixation was planned, and for this, we opted to perform "double hitch stitch" method. Informed consent from the patient has been obtained before each interventional procedure. The steps were as follows:

Step 1. After rigid bronchoscopy under general anesthesia, the stitch site was selected by

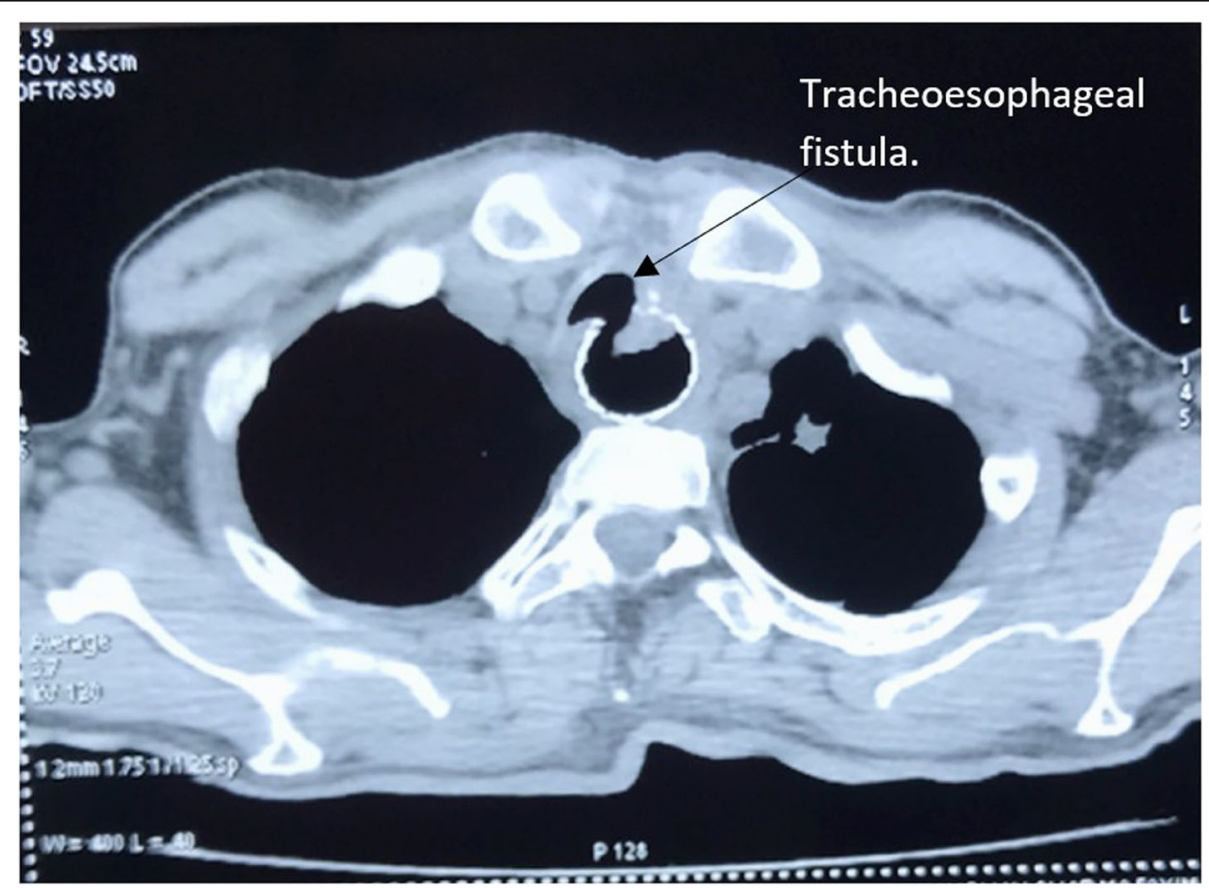

Fig. 1 CT chest showing tracheoesophageal fistula at the level of proximal margin of esophageal stent 


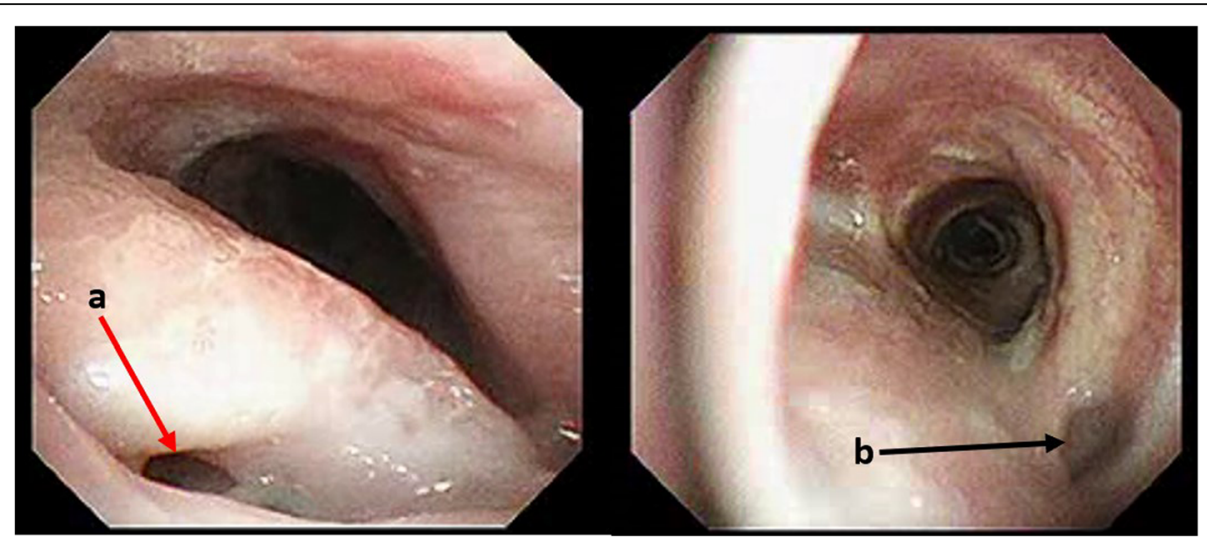

Fig. 2 The first bronchoscopy of the patient which shows 2 fistulous openings. One opening is represented by red arrow (a) $3 \mathrm{~cm}$ below vocal cords on posterior wall of trachea and another one represented by black arrow (b) $1 \mathrm{~cm}$ above carina on the right tracheal wall

bronchoscopically observing the indentation caused by external forceps to confirm placement within the body of the stent. Indentation is the depression on the anterior wall of the trachea which is caused by external pressure of forceps on the anterior aspect of the neck and observed bronchoscopically.

Step 2. A small skin (subcutaneous) incision (8-10 $\mathrm{mm}$ ) was given on the anterior aspect of the neck. A 16-G 2-in. needle was then inserted percutaneously through the stent into its lumen, under visual guidance of a flexible bronchoscope passed through the rigid scope.
Step 3. A non-absorbable Ethilon straight suture was passed through the needle into the stent. The next step was to complete the loop by bringing this suture outside (Fig. 3a).

Step 4. To take this suture back through the stent lumen to the exterior, another non-absorbable Ethilon suture was inserted as a loop, through another 16-G percutaneous cannula, placed $5-7 \mathrm{~mm}$ away from the first suture, within the incision (Fig. 3b). Step 5. Under flexible bronchoscopy guidance, using flexible forceps, the first straight suture was pulled inside the loop (Figs. 3c and 4a).

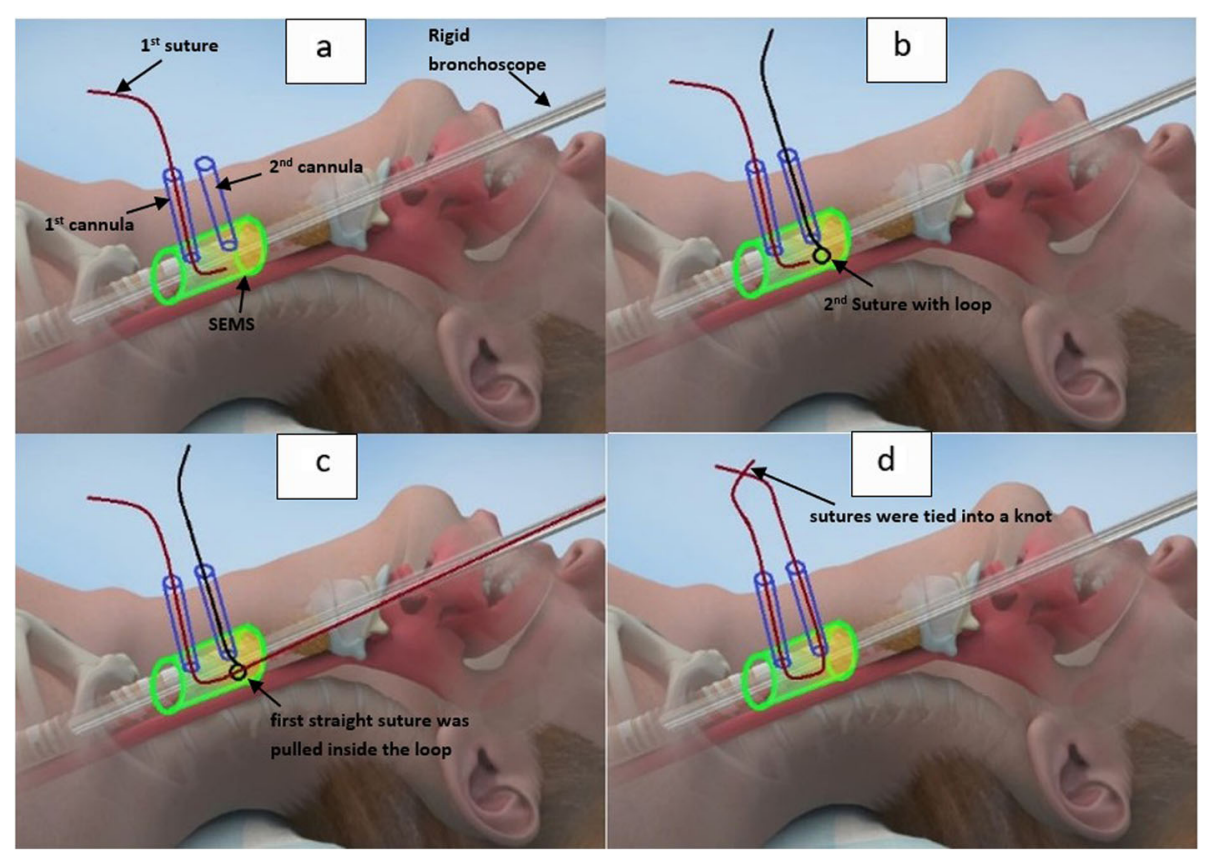

Fig. 3 Labeled animated representation of steps of double hitch stitch procedure 

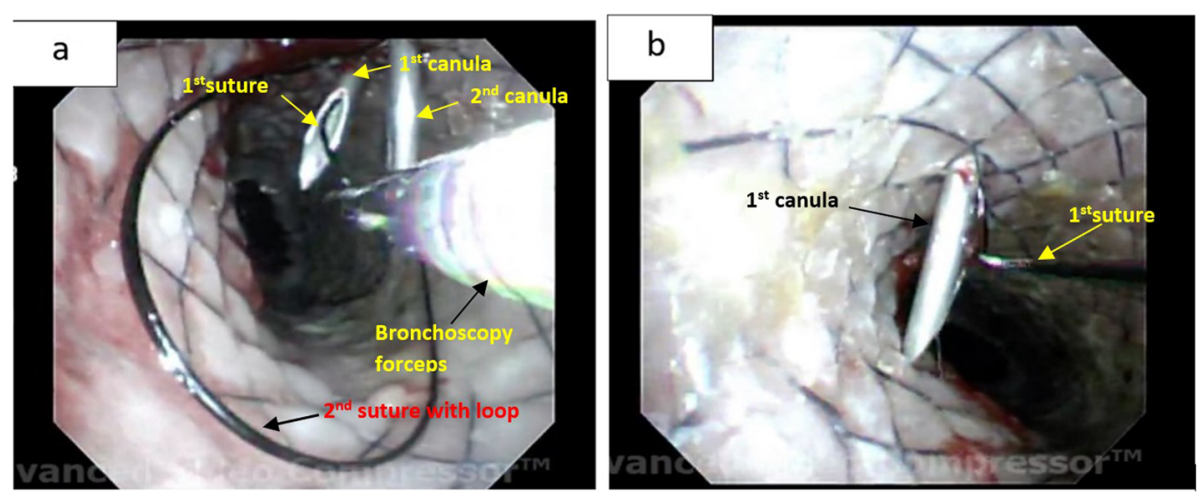

Fig. 4 Bronchoscopic image of double hitch stitch procedure

Step 6. With the straight suture pulled through the loop and held by the forceps, the looped suture was pulled out of the cannula, thus pulling out the straight suture through the second cannula (Fig. 4b).

Step 7. With both the ends of the straight suture outside, the two cannulas were pulled out. Both the ends of the straight suture were tied into a knot in the subcutaneous plane (Fig. 3d).
Step 8. Step 2 to Step 7 were repeated with a knot tied in a cross manner completing the double hitch stitch (Fig. 5).

Step 9. A final stitch was given on the skin outside the subcutaneous knots with an absorbable suture. Followup bronchoscopy after 1 month of double hitch stitch showed no migration of stent.

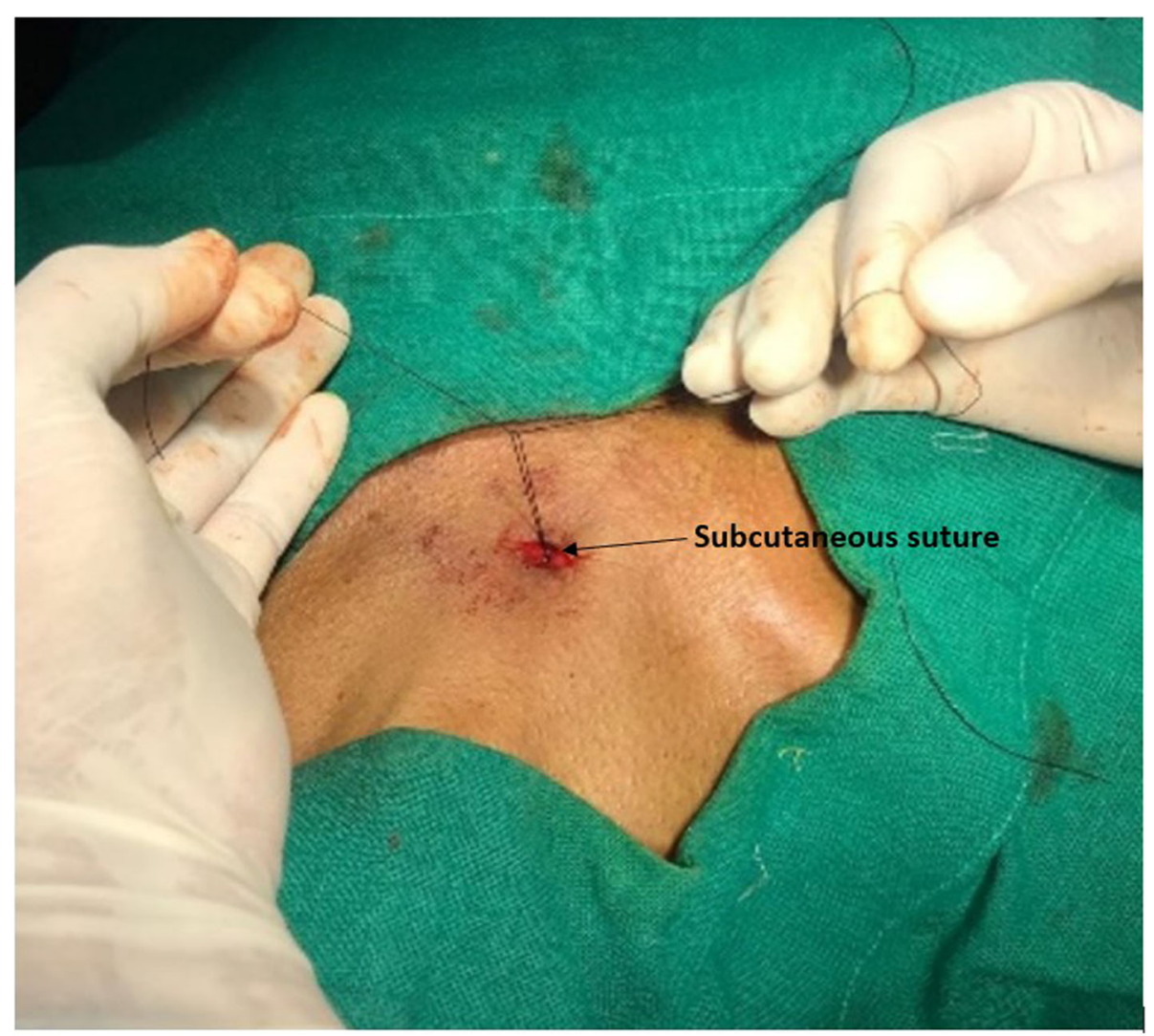

Fig. 5 Image of suture knot at subcutaneous level 
Procedure was well tolerated with good adherence assessed by history and radiological and bronchoscopic examination.

\section{Discussion}

The indication for placement of tracheal SEMS was made based on the current disease, anatomy, and clinical situation. Earlier in the course of the disease, an esophageal stent has been placed, but there was TOF leading to aspiration pneumonia. In the treatment of large tracheoesophageal fistulas, stenting of both the trachea and the esophagus is superior to single stenting of either tract. We have done the tracheal stenting with SEMS, and later, migration of tracheal SEMS occurred. Esophageal malignancy had led to erosion of tracheal wall and esophageal stent being relatively much larger in size as compared to tracheal stent, must have exerted the radial force leading to displacement of the tracheal stent from its original position. Another explanation can be relatively high position of the stent in the trachea. Proximal position of stent is also a risk factor for migration. Displacement of the metallic stents although very rare is a documented complication in malignancy cases [8]. The real challenge was to do stenting of both the trachea and esophagus together and to maintain stent position. Hitch stich is a very rare and advanced interventional pulmonology procedure performed for fixation of tracheal stents. There are several external fixation strategies that have been tried over 2 decades to maintain stent position, as shown in the studies of Miwa et al. [4], Colt et al. [5], Majid et al. [6], and Musani et al. [9]. All these approaches have positives and negatives. Hitch stitch procedure is especially beneficial for TOF cases requiring firm positioning of tracheal as well as esophageal stent to prevent migration [7]. We repositioned the metallic stent and performed the "double hitch stitch," in which the stent was anchored to the trachea through two stitches which were tied outside the neck but inside the subcutaneous tissue leaving no scar at all.

There were less chances of infection at the stitch site as it was percutaneous. The procedure although challenging was performed without any complication. Advantages of double hitch stitch procedure are mentioned in brief in Table 1. Patient was discharged in a few days and has been symptom-free post-procedure. In other

Table 1 Advantages of double hitch stitch procedure

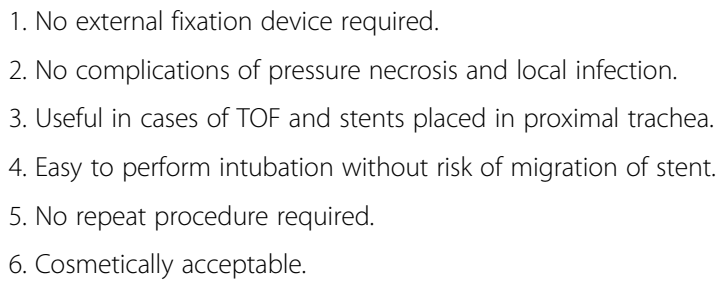

studies, as mentioned by author Colt et al. and Majid et al., stent fixation was done using a foreign body-like button over the skin. These studies have documented complications such as subcutaneous infection through polypropylene button and swallowing discomfort due to movement of button and embedding a silicone button in the subcutaneous tissue. Usage of metal clamp on the surface of the neck was described by Musani et al., which led to localized cellulitis and suture breakage. In our study, the sent fixation was done subcutaneously which has the advantage of avoiding any foreign body which might cause pressure necrosis and local infection [6]. Mehta et al. have performed the hitch stitch procedure with single stitch [7]. We have performed similar procedure with a double stitch with an advantage of ensuring better fixation, reducing the chances of stent migration. The procedure was highly efficient as follow-up bronchoscopy after 1 and 6 months showed no migration of either of the two stents. The procedure was patient friendly because he lives in a remote place where finding an experienced interventional pulmonologist is difficult, and after double hitch stitch, there was no need to perform repeat procedure. Double hitch stitch for preventing stent migration is proved to be a lifesaving procedure in this case of aspiration pneumonia caused by tracheoesophageal fistula.

\section{Conclusion}

Double hitch stitch procedure was a simple, safe, and feasible method for overcoming and preventing stent migration without any post-procedural complications in case of large tracheoesophageal fistula.

\section{Abbreviations}

SEMS: Self-expandable metallic stent; CT: Computed tomography;

UGIE: Upper gastrointestinal endoscopy; EUS: Endoscopic ultrasound;

FNAC: Fine needle aspiration cytology; TOF: Tracheoesophageal fistula

\section{Acknowledgements}

We thank our colleague and Dr. Swapnil Bakamwar for assisting the whole procedure of hitch stitch in the operation room. We thank Hemant Balapure, technician, KRIMS hospital, Nagpur, India, for assisting in the bronchoscopy procedure.

\section{Authors' contributions}

All authors had substantial contributions to the conception of the case report. All authors were active participants in the drafting and revising of the case report. All authors approved of the final version of manuscript. All authors agree to be accountable for all aspects of the work. All authors were directly involved in this patient's care in the operating room and contributed to the writing and editing of this manuscript. PD researched and wrote the patient background and pulmonary history. SC researched and wrote the abstract and conclusion of the manuscript and captured and arranged the images. SA conceptualized the process; researched, compiled, and wrote the procedure, conclusion, and introduction; and served as the overall editor.

Funding

Nil.

Availability of data and materials Provided in this case report. 


\section{Declarations}

\section{Ethics approval and consent to participate}

Ethics has approved this study.

\section{Consent for publication}

The authors certify that they have obtained appropriate patient consent form. In the form, the patient has given his consent for his images and other clinical information to be reported in the journal. The patient understand that his name will not be published, and due efforts will be made to conceal his identity.

\section{Competing interests}

The authors declare that they have no competing interests.

Received: 26 December 2020 Accepted: 11 May 2021

Published online: 21 May 2021

\section{References}

1. McGaw C, Alkaddour A, Vega KJ, Munoz JC (2016) Stent type used does not impact complication rate or placement time but can decrease treatment cost for benign and malignant esophageal lesions. World J Gastrointest Endosc. 8(7):338-343. https://doi.org/10.4253/wjge.v8.i7.338

2. Saito Y, Imamura H (2005) Airway stenting. Surg Today. 35(4):265-270. https://doi.org/10.1007/s00595-004-2942-y

3. Bolliger CT, Probst R, Tschopp K, Solèr M, Perruchoud AP (1993) Silicone stents in the management of inoperable tracheobronchial stenoses: indications and limitations. Chest. 104(6):1653-1659. https://doi.org/10.1378/ chest.104.6.1653

4. Miwa K, Takamori S, Hayashi A, Fukunaga M, Shirouzu K (2004) Fixation of silicone stents in the subglottic trachea: preventing stent migration using a fixation apparatus. Ann Thorac Surg. 78(6):2188-2190. https://doi.org/10.101 6/.athoracsur.2003.10.085

5. Colt HG, Harrell J, Neuman TR, Robbins T (1994) External fixation of subglottic tracheal stents. Chest. 105(6):1653-1657. https://doi.org/10.1378/ chest.105.6.1653

6. Majid A, Fernandez-Bussy S, Kent M, Folch E, Fernandez L, Cheng G, Gangadharan SP (2012) External fixation of proximal tracheal airway stents: a modified technique. Ann Thorac Surg 93:e167-el69

7. Mehta RM, Singla A, Shah A, Chakravarthi L (2017) "Hitch Stitch" to prevent stent migration. Respiration. 93(2):106-111. https://doi.org/10.1159/000453075

8. Singh P, Singh A, Singh A, Sharma G, Bhatia PK, Grover AS (2016) Long-term outcome in patients with esophageal stenting for cancer esophagus - our experience at a rural hospital of Punjab, India. J Clin Diagn Res 10(12):PC06PC09. https://doi.org/10.7860/JCDR/2016/22950.8994

9. Musani Al, Jensen K, Mitchell JD, Weyant M, Garces K, Hsia D (2012) Novel use of a percutaneous endoscopic gastrostomy tube fastener for securing silicone tracheal stents in patients with benign proximal airway obstruction. J Bronchology Interv Pulmonol 19(2):121-125. https://doi.org/10.1097/LBR. Ob013e318251e238

\section{Publisher's Note}

Springer Nature remains neutral with regard to jurisdictional claims in published maps and institutional affiliations.

\section{Submit your manuscript to a SpringerOpen ${ }^{\mathcal{O}}$ journal and benefit from:}

- Convenient online submission

- Rigorous peer review

- Open access: articles freely available online

- High visibility within the field

- Retaining the copyright to your article 